\title{
DEVELOPMENT OF SOCIAL SKILL SCALE FOR EARLY CHILDHOOD
}

\author{
Sri Budyartati \\ Postgraduate Yogyakarta State University \\ IKIP PGRI MADIUN \\ budyartatisri@gmail.com
}

\begin{abstract}
Abstact
Many social skills may be learned implicitly, all children can benefit from being taught social skills explicitly, not only children who are developmentally lagging behind their peers. Social skills are not always learned easily. Some children may require repeated instruction and reinforcement of learning. It is also possible for children to have well-developed social skills in one area but not in another. The primary objective of the Social Skill Scale (SSS) is to describe the child's behavior for purposes of socialization and education, rather than diagnosis. It focuses on the child's adaptation to and functioning within his or her environment which is particularly relevant to teachers. The SSS helps teachers design classroom interventions that address both the child's strengths and weaknesses. It includes 115 items that can be completed in just 15 minutes by Early Childhood, a preschool, or Kindergarten teacher. These items cover Three basic scales and ten components or summary scales
\end{abstract}

Keywords: Development, Social Skill Scale

\begin{abstract}
Abstrak
Banyak keterampilan sosial dapat dipelajari secara implisit, semua anak bisa mendapatkan keuntungan dari keterampilan sosial yang diajarkan secara eksplisit, tidak hanya anak-anak yang tertinggal perkembangan dari rekan-rekan mereka. Keterampilan sosial tidak selalu dipelajari dengan mudah. Beberapa anak mungkin memerlukan pengulangan instruksi dan penguatan pembelajaran. Hal ini juga berlaku bagi anak-anak untuk memiliki keterampilan sosial yang berkembang dengan baik di satu area tetapi tidak begitu baik di ranah lain. Tujuan utama dari Skala Keterampilan Sosial ini adalah untuk menggambarkan perilaku anak yang ditujukan bagi sosialisasi dan dunia pendidikan, bukan sekedar diagnosis. Ini berfokus pada adaptasi anak dan fungsinya dalam lingkungan yang sangat relevan dengan guru, membantu guru merancang intervensi kelas dengan membahas kekuatan dan kelemahan anak. Ini mencakup 115 item yang dapat diselesaikan hanya dalam 15 menit dengan mengamati Anak Usia Dini, Usia prasekolah, oleh gurunya Item ini mencakup Tiga skala dasar dan sepuluh komponen atau skala Ringkasan
\end{abstract}

Kata Kunci: Pengembangan, Skala Keterampilan Sosial 


\section{A. Pendahuluan}

Keterampilan sosial adalah perilaku yang ditampilkan yang didalamnya memuat banyak aspek kecerdasan. Seperti halnya pengukuran hasil belajar yang meliputi tiga domain, yaitu wilayah kognitif, afektif dan psikomotor. Pengukuran keterampilan sosial sudah seharusnya juga meliputi banyak aspek kecerdasan. Hal tersebut dikarenakan keterampilan secara sosial merupakan akumulasi dari banyak kecerdasan.

Pengukuran keterampilan sosial yang telah dilakukan sejauh ini belum mengukur keterampilan sosial secara komprehensip. Hal itu dikarenakan test keterampilan sosial yang dikembangkan berasal dari dimensi kognitif. Pernyataan di atas didukung oleh hasil-hasil penelitian yang dituliskan oleh Daniel Goleman (2007; 333). Korelasi yang tinggi antara hasil pengukuran kecerdasan dengan hasil tes IQ, yang menunjukkan tidak ada perbedaan nyata antara kemampuan kognitif dan bakat sosial, mungkin menjadi alasan utama penelitian kecerdasan sosial ditinggalkan sebagian besar peneliti.

Menurutnya, definisi kecerdasan sosial itu tampaknya hasil dari kecondongan kemampuan kognitif yang diterapkan pada arena sosial. Permasalahannya dimulai dari pendekatan cara menilai bakat interpersonal menjadi sekedar pertanyaan, misalnya, untuk mengetahui apakah orang setuju dengan pernyataan seperti "Saya dapat memahami perilaku orang lain" dan "saya tahu bagaimana tindakan saya membuat orang lain merasakannya". Harus disadari bahwa permasalahan ini adalah yang paling mendasar dalam pengukuran keterampilan sosial. Pengukuran keterampilan sosial hanya sebatas pada aspek-aspek verbal saja atau baru sampai pada melihat dan menilai pilihan kata.

Senada dengan temuan Goleman di USA, maka di Indonesia, Djohan (2009) juga melakukan hal sama. Di mana pengukuran keterampilan sosial semata-mata diturunkan dari aspekaspek kecerdasan sosial di dalam penelitian yang berjudul Musical Ability as A Mean of Development of Social Skills dimaksudkan "Kemampuan Musikalitas Sebagai Sarana Pengembangan Keterampilan Sosial". Penelitian Djohan bertujuan untuk mengembangkan sebuah alat pengukuran kemampuan musikalitas yang dapat menggambarkan kepekaan anak terhadap seni dan musik. Menurutnya, bersamaan dengan itu dikarenakan belum tersedianya alat ukur keterampilan sosial yang teruji menyebabkan perlunya dikembangkan sebuah alat ukur kecerdasan sosial yang dapat memberikan gambaran tentang kemampuan dan keterampilan siswa dalam menjalin relasi dengan orang lain, sehingga keduanya dapat bersama-sama memberikan sumbangan terhadap pendidikan dasar anak-anak.

$$
\text { Dapat dikatakan bahwa }
$$
sejauh ini kecerdasan sosial ditandai masih sebatas identik kemampuan kognitif murni, didefinisikan kecerdasan sosial, sebagai "kemampuan untuk memahami orang lain dan bagaimana mereka akan bereaksi terhadap situasi sosial yang berbeda" 


\section{B. Pembahasan}

\section{Dimensi Kecerdasan Emosional}

Robin Stern, Ph.D. adalah Direktur Riset dan Pengembangan Media Baru di Pusat Pendidikan Sosial dan Emosional di Teachers College, Columbia Univeristy. Stern adalah seorang pendidik dan konsultan psikologis pada isu-isu perempuan dan teknologi di sekolahsekolah, perusahaan, museum dan perusahaan digital media. Penelitian Sterns berkepentingan dalam penggunaan teknologi untuk meningkatkan kompetensi emosional, dalam wilayah perempuan muda dan kepemimpinan. Dalam What is it?

How can we use it to help our children mengupas kecerdasan emosional sebagai berikut: Kecerdasan emosional (EQ) bukanlah konsep baru, pada masa Socrates, yang memiliki saran katakata bijak:Kenali Diri. Ratusan tahun kemudian, mulai dirumuskan filsafat Sokrates ke dalam apa yang kini telah menjadi dikenal sebagai pembelajaran sosial dan emosional (SEL). Proses pembelajaran dengan cita-cita untuk EQ yang lebih tinggi. Studi menunjukkan bahwa EQ adalah prediktor terbaik prestasi masa depan prestasi anak; lebih baik daripada faktor tunggal lainnya. EQ adalah prediktor kesuksesan yang lebih baik daripada gabungan IQ dan keterampilan teknis.

Bidang pembelajaran sosial dan emosional (SEL) telah muncul dari pemahaman-pemahaman baru tentang sifat biologi, emosi dan kecerdasan dan hubungannya dengan keberhasilan dan kebahagiaan. Melalui kecerdasan emosional anakanak belajar sosial dan emosional
(EQ) yang didukung, yang memberi mereka keunggulan pribadi dan profesional yang sangat besar di masa depan mereka. Keterampilan apakah yang menjadi prediktor terbaik untuk sukses secara akademis dan kehidupan? Mengapa beberapa anak tumbuh terpenuhi menjadi orang dewasa dalam karir menantang dan hubungan yang memuaskan, sementara anak lainnya, dari latar belakang dan kinerja akademik yang mirip, penuh perjuangan dalam hubungan, buntu kariernya dan depresi? Semakin banyak pendidik mengakui bahwa siswa yang menerima pendidikan akademis secara eksklusif mungkin kurang dilengkapi untuk tantangan masa depan, baik sebagai individu dan anggota masyarakat - yang tidak cukup hanya memberi makan pikiran.

Pada 1980-an, Howard Gardner, dalam karya penting tentang kecerdasan ganda, diuraikan adanya tujuh domain kecerdasan, dua dari tujuh tersebut adalah interpersonal dan intrapersonal gabungan ini adalah cikal bakal dari apa yang sekarang kita kenal sebagai kecerdasan emosional. Istilah ini pertama kali diciptakan oleh Peter Salovey, profesor dan psikolog di Yale University, dan John Mayer, profesor dan psikolog di University of New Hampshire. Pada tahun 1995 Daniel Goleman, ahli terkemuka di bidang ini, melaporkan "IQ adalah hanya prediktor kecil kesuksesan dalam hidup, sementara keterampilan sosial dan emosional adalah prediktor dari keberhasilan dan kesejahteraan yang jauh lebih baik dari pada kecerdasan akademis. 
Pelaporan Daniel Golemans yang luar biasa dan penelitiannya tentang kompetensi sosial dan emosional pada tahun 1995 dalam bukunya mengenai Kecerdasan Emosional, membawa konsep ini ke dalam fokus yang sangat dibutuhkan. Pekerjaan Goleman mengajarkan kita bahwa keterampilan sosial dan emosional anak-anak dapat dibudidayakan, sehingga anak akan bertambah baik itu keuntungan jangka pendek serta jangka panjang dalam hal kesejahteraan, kinerja dan keberhasilan dalam hidup. Dia menguraikan lima kompetensi emosional penting yang menjadi dasar untuk pembelajaran sosial dan emosional:

1) Self and other awareness: understanding and identifying feelings; knowing when one's feelings shift; understanding the difference between thinking, feeling and acting; and understanding that one's actions have consequences in terms of others' feelings.

2) Mood management: handling and managing difficult feelings; controlling impulses; and handling anger constructively,

3) Self-motivation: being able to set goals and persevere toward them with optimism and hope, even in the face of setbacks.

4) Empathy: being able to put yourself "in someone else's shoes" both cognitively and affectively; being able to take someone's perspective; being able to show that you care.

5) Management of relationships: making friends, handling friendships; resolving conflicts; life. The difference, Corner claims, is equal to the difference in the outcome of throwing seeds on cement versus planting seeds in enriched soil.

\section{Dimensi Kecerdasan Sosial}

Ada yang menganggap bahwa ketrampilan sosial hanyalah bagian kecil dari kompetensi sosial, misalnya: Kompetensi Sosial adalah susunan multilevel yang terdiri dari tiga tingkat sub: (a) penyesuaian sosial, (b) kinerja sosial, dan (c) keterampilan sosial (Cavell, 1990). Kinerja sosial (berfungsi sebagai) bangunan lain yang didefinisikan oleh Cavell (1990), sebagai (a) pencapaian sosial, (b) penilaian global kompetensi sosial dan (c) penerimaan sosial.

Sementara itu, Djohan, (2009) Kecerdasan sosial anak terdiri dari dimensi dimensi:1. kepekaan terhadap perasaan orang lain,2. kemampuan membedakan struktur masalah,3. kemampuan menganalisis persoalan,4. kemampuan untuk memecahkan masalah dan berpikir logis,5. kemampuan kreativitas yang membangun,6. kemampuan mengekspresikan pikiran, perasaan, dan gagasan pada orang lain,7 kemampuan melakukan komunikasi dan bekeria sama dengan orang lain.

$$
\text { Goleman }
$$

mengusulkan, sarana kecerdasan sosial di sini dapat dibagi dalam dua kategori besar: kesadaran sosial, apa yang kita rasakan tentang orang laindan fasilitas sosial, apa yang kita lakukan kemudian dengan kesadaran itu. Kesadaran sosial mengacu pada spektrum penginderaan keadaan batin orang lain yang berjalan secara iristantaneous, untuk memahami perasaan dan pikiran,untuk 
"mendapatkan" situasi sosial yang rumit. Hal ini termasuk "primal empati": Merasakan keadaan orang lain; penginderaan sinyal emosional nonverbal. "Attunement": Mendengarkan seseorang. "ketepatan empatik": Memahami pikiran orang lain, perasaan, dan niatannya. "Kognisi Sosial": Mengetahui bagaimana dunia sosial bekerja. Fasilitas sosial secara sederhana digambarkan bagaimana merasakan rasanya orang lain, atau mengetahui niatan apa yang mereka pikirkan, tidak menjamin interaksi yang bermanfaat, fasilitas sosial didasarkan pada kesadaran sosial untuk yang memungkinkan diikuti secara halus, interaksi efektif. Spektrum fasilitas sosial meliputi:sinkroni: Berinteraksi dengan lancar secara nonverbal, Selfpresentasi: kehadiran sosok diri

secara efektif., Pengaruh: Membentuk hasil interaksi sosial, Kepedulian: Peduli tentang kebutuhan orang lain dan bertindak yang sesuai.

Both the social awareness and social facility domains range from basic, low-road capacities, to more complex high-road articulations. For instance, synchrony and primal empathy are purely low-road capacities, while empathic accuracy and influence mingle high and low. And as "soft" as some of these skills may seem, there are already a surprising number of tests and scales to assess them Goleman (2007).

Sinkroni dan empati dasar adalah murni kapasitas jalan-rendah, sementara ketepatan empatik dan pengaruh berbaur tinggi dan rendah. Dan sebagai hal"lunak" karena beberapa keterampilan yang mungkin tampak, sudah ada sejumlah mengejutkan tes dan skala untuk menilai mereka.

Tabel 1. Klasifikasi Unsur-Unsur Kecerdasan Sosial Menurut Goleman

\begin{tabular}{|c|c|}
\hline Kesadaran Sosial, & $\begin{array}{c}\text { Fasilitas } \\
\text { Sosial, }\end{array}$ \\
\hline $\begin{array}{l}1 \text { "Primal Empati": } \\
\text { merasakan keadaan } \\
\text { orang lain; } \\
\text { penginderaan sinyal } \\
\text { emosional } \\
\text { nonverbal. }\end{array}$ & $\begin{array}{l}\text { Sinkroni: } \\
\text { berinteraksi } \\
\text { dengan lancar } \\
\text { secara } \\
\text { nonverbal, }\end{array}$ \\
\hline $\begin{array}{l}2 \text { "Attunement": } \\
\text { mendengarkan } \\
\text { dengan seseorang. }\end{array}$ & $\begin{array}{l}\text { Self-Presentasi: } \\
\text { Kehadiran } \\
\text { Sosok Diri } \\
\text { Secara Efektif., }\end{array}$ \\
\hline $\begin{array}{l}3 \text { "Ketepatan } \\
\text { Empatik":memahami } \\
\text { pikiran orang lain, } \\
\text { perasaan, dan } \\
\text { niatannya. "“ }\end{array}$ & $\begin{array}{l}\text { Pengaruh: } \\
\text { membentuk } \\
\text { hasil interaksi } \\
\text { sosial,, }\end{array}$ \\
\hline $\begin{array}{l}4 \text { Kognisi Sosial": } \\
\text { mengetahui } \\
\text { bagaimana dunia } \\
\text { sosial bekerja }\end{array}$ & $\begin{array}{l}\text { Kepedulian: } \\
\text { peduli tentang } \\
\text { kebutuhan } \\
\text { orang lain dan } \\
\text { bertindak yang } \\
\text { sesuai. }\end{array}$ \\
\hline
\end{tabular}

Ada banyak definisi mengenai kecerdasan sosial dari para ahli, Untuk lebih jelasnya dapat dilihat dalam definisi keterampilan sosial menurut Djohan, Goleman dan Cavell, tersebut di atas. Jika diperhatikan terdapat hal-hal yang mirip secara esensial.

\section{Dimensi Kecerdasan Budaya}

Di muka telah disinggung mengenai pengembangan tes keterampilan sosial harus menimbang kecerdasan sosial yang berkaitan erat dengan hubungan antar manusia. Pada saat membahas keterampilan sosial tidaklah sematamata membahas kemampuan bersosialisasi. Namun keterampilan sosial melibatkan customs dan 
culture. Sebagaimana ungkapan Brooks Peterson (2004) dalam buku Cultural Intelligence: A Guide to Working with People from Other Cultures.

"Some might argue that these are just different ways of making conversation. But I maintain that the questions we ask, the conversations we have, the topics we consider appropriate, and the way we approach those topics all represent a deeper cultural programming. When the cultural programming between businesspeople from two sides is different enough, (they may ultimately choose not be able to do business together) to not do business with others (2004:88).

Berdasarkan kutipan di atas dapat dijelaskan bahwa keterampilan sosial adalah suatu bidang yang amat luas cakupannya. Jika dalam pembelajaran kita mengenal istlah continuum learning untuk menggambarkan luasnya cakupan isi materi pelajaran yang harus dikuasai siswa maka traits psikologis dalam ketrampilan sosial meliputi kecerdasan intellectual, kecerdasan emosional, dan kecerdasan budaya.

Definisi kecerdasan budaya dalam kaitannya dengan keterampilan sosial seseorang dapat dilihat dalam kutipan berikut, "Kecerdasan budaya adalah kemampuan untuk terlibat dalam serangkaian perilaku yang menggunakan keterampilan (yaitu, bahasa atau keterampilan interpersonal) dan kualitas (misalnya, toleransi terhadap ambiguitas, fleksibilitas) yang disetel dengan tepat terhadap nilai-nilai berbasis budaya dan sikap seseorang dengan interaksinya." (Brooks, 2004)
Dapat disimpulkan bahwa kecerdasan budaya merupakan sutu petunjuk untuk dapat bekerja sama dengan orang lain dari tradisi, budaya, kultur yang berbeda.

Continum learning dalam kecerdasan budaya ini memiliki lima aspek yang terentang dari skala satu sampai dengan sepuluh angka

\begin{tabular}{lll}
\hline No & $\begin{array}{c}\text { Dimulai } \\
\text { dari }\end{array}$ & $\begin{array}{c}\text { Sampai } \\
\text { Dengan }\end{array}$ \\
\hline 1 & Equality & Hierarchy \\
\hline 2 & Direct & In Direct \\
\hline 3 & Individual & Group \\
\hline 4 & Task & Relationship \\
\hline 5 & Risk & Caution \\
\hline & Sumbangan & Continum
\end{tabular}

learning dalam kecerdasan budaya ini dalam pengembangan alat ukur keterampilan sosial adalah beberapa aspek dalam keterampilan sosial akan diambil dari aspek kecerdasan budaya, misalnya bekerja sama dengan orang lain atau cooperative adalah salah satu inti dari

"Relationship" seperti yang dimaksud dalam aspek kecerdasan budaya di atas.

\section{Keterampilan Sosial Pada Anak Usia Dini Dan Tahap Perkembangan Anak Usia Dini}

Pendidikan Anak Usia Dini (PAUD) adalah suatu upaya pembinaan yang ditujukan kepada anak sejak lahir sampai dengan usia enam tahun yang dilakukan melalui pemberian rangsangan pendidikan untuk membantu pertumbuhan dan perkembangan jasmani dan rohani agar anak memiliki kesiapan dalam memasuki pendidikan lebih lanjut

Dalam menilai keterampilan sosial anak, penting untuk diingat tonggak perkembangan sosial yang normal sesuai dengan usia anak. 
Panduan berikut menunjukkan perkembangan sosial keterampilan yang sesuai untuk berbagai usia. Namun harus diingat bahwa tidak ada ketentuan waktu perkembangan universal. Juga, banyak keterampilan tercantum berikut ini lebih seperti karya yang berlangsung dari tonggak prestasi, mereka berkembang secara perlahan selama bertahun-tahun,

secara bertahap menjadi lebih canggih dan mapan. (http://www.nasponline.org/resource s/factsheets/social skills fs.aspx)

Keterampilan tercantum yang berikut ini berupa perilaku. Perilaku Sosial Usia 2 Tahun: Kesadaran

sosial sangat terbatas. Bermain cenderung untuk menyendiri, meskipun masa balita ini akan mengamati dan meniru orang dewasa dan anak-anak lain. Interaksi berlangsung minimal,selain perselisihan tentang mainan

Perilaku Sosial Usia 3 Tahun: Mengembangkan Bermain paralel: anak- anak bermain bersama satu sama lain, dengan beberapa interaksi.2 belajar untuk berbagi dan mengambil gilirannya. Mulai belajar untuk mengelola agresi fisik.

$$
\text { Perilaku Sosial Usia 4-5 }
$$

Tahun :Permainan yang perlu kerjasama mulai berkembang. 2.anak-anak mulai untuk bermain permainan kelompok. Permainan menjadi lebih kompleks dan terorganisir. 3. Persahabatan 'Special' mulai terbentuk. 4. Belajar cara-cara bermain secara adil dan mematuhi orang lain pendekatan aturan main. 5 . dapat melakukan pendekatan dengan orang lain dan meminta untuk bergabung dengan kelompok. Mulai belajar untuk bersikap tegas dan meminta orang lain untuk berhenti jika mereka bersikap menjengkelkan.

Perilaku Sosial Usia 6-8 Tahun :1. Belajar untuk menjadi 'pemenang baik' dan 'pecundang baik' .2 Bisa berempati dengan orang lain dalam kesulitan dan menawarkan dukungan. 3.belajar keterampilan yang tepat untuk memberi dan menerima pujian dari otorang lain. .4. Percakapan berkembang: bagaimana mendengarkan orang lain dan bergantian berbicara, dan lainlainnya.5. dapat meminta dukungan orang dewasa untuk ketika dibutuhkan.6. keterampilan negosiasi: termasuk orang lain dalam pengambilan keputusan, belajar untuk memutuskan bersama dan membuat saran, bukan orang lain.7. dapat untuk berkata 'tidak' untuk teman-teman saat yang tepat.

Perilaku Sosial Usia Usia912: berbicara dengan penuh percaya diri di depan kelompok. Belajar untuk menghargai pendapat orang lain. Keterampilan sosial yang kompleks dan multi-faceted.

Berkaitan erat dengan pengembangan. Keterampilan sosial anak berusia lima tahun jelas tidak akan cukup untuk bernegosiasi dunia sosial melayani yang lebih kompleks dari dua belas tahun yang lebih tua.

Secara lebih spesifik, perilakuperilaku di atas berdasarkan domains kompetensi sosial terdiri dari. a Dasar interaksi keterampilan (misalnya, tersenyum, membuat kontak mata, mendengarkan)b.

keterlibatan/pendekatan keterampilan (bagaimana mendekati seseorang secara sosial atau bergabung dengan grup)c. Pemeliharaan keterampilan (misalnya, bagaimana untuk 
berbagi,bergiliran, ikuti aturan, rekan beroperasi dll) d. keterampilan Persahabatan (misalnya, bagaimana menunjukkan kasih sayang yang tepat,melibatkan orang lain dalam pengambilan keputusan, bersifat inklusif, dll)e.Resolusi konflik(bagaimana mengelola perbedaan pendapatdengan cara yang diterima secara sosial)f. Empati g.Komunikasi kebutuhan dan ide-ide h.Rasa humor , i.Ketegasan (bagaimana mengatakan tidak untuk terlibat dalam perilaku berbahaya atau antisosial,membela diri, dll). Mengingat hubungan erat antara keterampilan sosial dan keamanan sekolah, sekolah semakin mencari cara untuk membantu siswa mengembangkan keterampilan sosial yang positif, baik di sekolah dan di masyarakat.

Keterampilan sosial yang terkait dengan keselamatan sekolah meliputi: a. Manajemen kemarahan, b. Mengenali/memahami titik pandang orang lain, c. Pemecahan masalah Sosial, d Negosiasi antar rekan, e. Manajemen konflik, f. Keterampilan perlawanan rekan, g.Aktif mendengarkan, h.Komunikasi yang efektif, i.Peningkatan penerimaan dan toleransi dari beragam kelompok http://www.nasponline.org/ resources /factsheets/socialskills fs.aspx)

Mencoba menggambarkan lahirnya konsep "Social Skill Autopsi” Rick Lavoie (2005) memaparkan sebuah cerita, di mana kejadian ini melahirkan konsep "Social Skill Autopsi" Teknik ini sekarang digunakan di sekolahsekolah dan rumah-rumah di seluruh Amerika Utara dan telah efektif dalam meningkatkan kompetensi sosial ribuan anak. Strategi ini didasarkan pada tiga prinsip dasar : 1. Kebanyakan kesalahan keterampilan sosial yang tidak disengaja. Hal ini diterima secara universal bahwa kebutuhan primer semua manusia adalah disukai dan diterima oleh manusia lain. Oleh karena itu, jika seorang anak melakukan sendiri dengan cara yang menyebabkan orang lain untuk tidak menyukai atau menolak dia, bisa kita tidak berasumsi bahwa perilaku yang tidak disengaja dan jauh di luar kendali anak? Mengapa seorang anak sengaja mengalahkan salah satu kebutuhan primer nya?; 2. Jika Anda menerima premis bahwa perilaku menyinggung yang tidak disengaja, menjadi jelas bahwa menghukum anak untuk kesalahan keterampilan sosial tidak adil, tidak pantas, dan tidak efektif. 3. pendekatan tradisional dengan pemulihan keterampilan sosial tidak efektif. Strategi-strategi-role-playing, demonstrasi, rekaman video, ceramah, diskusi-jarang memiliki dampak positif pada pengembangan kompetensi sosial anak-anak. Mereka mungkin memiliki efek jangka pendek sementara, tetapi hasilnya jarang yang abadi dan tidak sering generalisasi ke pengaturan lain.

\section{Manfaat Dan Tujuan PenilaiaN a. Tujuan Penilaian}

Setiap disain pembelajaran terdapat dua aspek, yaitu:Instructional dan Nurturance. Selama ini dunia pendidikan di Indonesia lebih banyak mengedepankan instructional dan kurang memperhatikan nurturant, pembelajaran terpisah dari kehidupan 
nyata. Padahal pendidikan yang ideal seharusnya meliputi instructional dan nurturant yang bersifat nyata dan seimbang,sehingga pembelajaran menjadi lebih bermakna.

Selama ini kehidupan sekolah dihabiskan untuk mengejar target berprestasi secara akademik. Padahal keberhasilan hidup dalam bermasyarakat tidak hanya berdasarkan akademik saja tetapi juga membutuhkan keterampilan sosial. Lembaga pendidikan memiliki potensi yang besar dalam mengembangkan keterampilan sosial jika dalam kurikulum memiliki porsi yang seimbang dan sejalan antara Instructional dan nurturant.

Sejauh ini keterampilan sosial kurang diperhatikan dalam pembelajaran. Padahal bangsa yang berkarakter harus memiliki keterampilan sosial yang memadai. Dengan kata lain keterampilan sosial adalah bagian penting dalam pendidikan karakter. Proses untuk mendapatkan keterampilan sosial dapat disebut bersosialisasi. Bersosialisasi bukan sekedar urusan berkumpul sepanjang waktu dengan teman sebaya. Tetapi ada sebuah tolok ukur yang dapat digunakan untuk menilai kualitas dan efektivitas bersosialisasi, yaitu keterampilan sosial.

Keterampilan sosial adalah kebutuhan penting buat setiap orang agar dapat hidup dan mengembangkan diri di masyarakat. UNESCO dalam APEID (1993), salah satu lembaga dalam Perserikatan Bangsa-Bangsa, bahkan memasukkan aspek-aspek Keterampilan Sosial sebagai bagian Keterampilan Hidup-KH (life skills) yang harus dipelajari anak- anak dalam pendidikannya. Keterampilan Hidup Sosial-KHS yang diperlukan untuk keberhasilan anak-anak menurut UNESCO antara lain adalah:

Interpersonal communication skills: Verbal/Nonverbal communication, Active listening, Expressing feelings; giving feedback (without blaming) and receiving feedback,Negotiation/refusal skills, Negotiation and conflict management, Assertiveness skills, Refusal skill

Empathy:

Ability to listen and understand another's needs and circumstances and express that understanding

Cooperation and Teamwork:

Expressing respect for others' contributions and different style,Assessing one's own abilities and contributing to the group,Advocacy Skill, Influencing skills \& persuasion, Networking and motivation skills

Mengajarkan keterampilan sosial merupakan tantangan para pendidik, bersosialisasi tidak boleh direduksi dengan pemaknaan sekedar bergaul dengan teman sebaya, tetapi harus melibatkan proses sadar untuk menguasai keterampilan sosial, sebagai contoh, misalnya pembelajaran pada bahasa selain mengajarkan kompetensi bahasa (mendengar,baca,tulis,dan berbicara)sekaligus merupakan wahana penanaman nilai kehidupan, budi pekerti dan menumbuhkembangkan keterampilan sosial yang diperlukan anak-anak agar mereka terampil saat terlibat di masyarakat di masa dewasanya nanti. 
Salah satu cara untuk memadukan antara tata nilai (sebagai bagian yang penting dalam memahami keterampilan sosial) dan kemampuan berbahasa adalah mengekspos anak dengan pilihan kata dan bahasa yang positif sejak dini. Pada waktu anak mulai berlatih membaca, kata-kata yang dipilih tidak harus berupa kata benda, tetapi pilihkan kata -kata sifat yang memiliki nilai positif (misalnya: cinta, sayang, adil, ramah, baik, pandai, damai, menolong, dan sebagainya) dan kurangilah ekspose kata-kata negatif (misalnya: jahat, benci, cengeng, iri, bodoh, culas, perang, dan sebagainya).

Ekspose yang kuat terhadap katakata yang positif bukan hanya berfungsi melatih keterampilan berbahasa anak dan membuat distingsi atau perbedaan bahasa,tetapi pilihan dan penguasaan kosa kata mempengaruhi tata nilai yang dominan pada anak. Selain berkaitan dengan tata nilai, kemampuan membuat distingsi bahasa (perbedaan yang tipis antar istilah) juga menunjukkan penguasaan pada satu bidang kehidupan. Seorang yang memiliki banyak pengetahuan tentang keuangan akan memiliki kosa kata yang lebih banyak mengenai uang dan perilaku uang dibandingkan orang lain. Seorang yang memiliki banyak pengetahuan tentang masakan, memiliki kosa kata yang sangat luas untuk mendeskripsikan nama benda, alat, proses, serta keadaan-keadaan yang berkaitan dengan dunia masakan.

Oleh karena itu, lihatlah kumpulan kosa kata yang kita miliki. Pada area apa yang banyak kita miliki, di situlah wilayah keahlian/kecerdasan kita. Jika kita ingin membantu anak menguasai sebuah area tertentu, salah satu strategi belajar yang dapat dilakukan adalah memperbanyak penguasaan kosa kata yang terkait dengan area itu.

Asesmen sebagai bagian yang strategis dalam dunia penilaian pendidikan, Namun sejauh ini penilaian pendidikan di dalam model sekolah cenderung bersifat akademik. Walaupun di dalam pendidikan ada tujuan-tujuan yang bersifat intelektual (kognitif), sikap (afektif), dan keterampilan/perbuatan (psiko-motorik); sebagian besar evaluasi yang digunakan di sekolah sangat menekankan aspek kognitif. Sekolah sangat mengutamakan penguasaan terhadap pengetahuan dan informasi yang terkandung di dalam sebuah mata pelajaran. Alat pengujian yang biasanya digunakan di sekolah adalah tes tertulis. Penilaian akademis model ujian tertulis sebenarnya disadari memiliki keterbatasan-keterbatasan. Tetapi, sampai saat ini model tersebut masih dianggap paling dapat digunakan secara massal untuk mengevaluasi dan membandingkan prestasi akademik siswa.

Salah satu model tidak terstuktur dalam asesmen (unstructured assesment) adalah mengamati minat dan kesungguhan anak-anak mempelajari sebuah bidang/hal yang diminatinya. Jika anak memiliki passion dan kebahagiaan untuk mengetahui sebuah area secara kontinyu, dapat dipastikan bahwa proses belajar sesungguhnya sedang terjadi. Model tidak terstruktur 
lainnya yang sering digunakan adalah pengamatan terhadap sikap dan perilaku anak. Pengajaran mengenai moralitas/dan karakter biasanya melibatkan evaluasi semacam ini. Pengajaran ini tidak dapat dinilai melalui ujian teoritis karena yang dipentingkan bukan penguasaan teori, tetapi sikap dan perilaku yang lahir sehari-hari. Oleh karena itu, untuk assesment pengajaran moral/karakter yang lebih dapat digunakan adalah model pengamatan atas perilaku sehari-hari.

Selain pengamatan, model tidak terstuktur lain yang sering digunakan adalah mengobrol, diskusi, dan bertukar pendapat antara orangtua dan anak. Dengan mengajukan pertanyaan-pertanyaan, orangtua dapat menggali pengetahuan, pendapat, dan sikap anak terhadap sebuah topik tertentu. Model ini dapat diterapkan secara informal yang memberikan peluang anak untuk menyatakan secara jujur mengenai pendapat-pendapatnya tanpa ada usaha untuk berpura-pura atau sekedar menyenangkan orang lain.

Model-model asesmen yang lebih terstruktur antara lain adalah proyek, portofolio karya, dan jurnal. Melalui proyek, orangtua dapat mengajarkan dan mengevaluasi proses belajar yang berhubungan dengan dunia nyata sehari-hari yang dekat dan diminati anak. Proyek akan membuat anak terlatih untuk menjalani proses sejak perencanaan, penyiapan logistik, hingga penyelesaiannya.

Jika anak memiliki minat dan keterampilan yang berorientasi output, kumpulan portofolio dapat menjadi alat bantu untuk memantau perkembangan anak. Karya tulis, gambar, lukisan, foto, video, cerita, adalah sebagian diantara karya anak yang dapat dikumpulkan. Salah satu instrumen lainnya adalah jurnal aktifitas, orangtua dan anak dapat membuat jurnal aktivitas sehari-hari yang dijalaninya. Kompleksitas jurnal disesuaikan dengan gaya orangtua dan anak,yang penting, jurnal itu dapat menjadi catatan perkembangan anak dan proses yang dilakukan oleh orangtua.

Dengan melihat uraian di atas maka tujuan penilaian keterampilan sosial itu adalah

1. Memberikan stimulus penerapan penilaian keterampilan sosial terhadap siswa yang dilakukan secara terstandardisasi.

2. Mengukur keterampilan sosial anak usia dini

3. Adanya kecenderungan proses belajar mengajar terpisah dari kehidupan nyata (real life).

4. Agar Pembelajaran menjadi lebih bermakna, misalnya pada tingkat PAUD mengurangi kecenderungan yang menekankan pada Pengajaran three / $3 \mathrm{r}$ (reading, writing, arithmatic)

5. Keterampilan sosial sebagai tolok ukur yang dapat digunakan untuk menilai kualitas dan efektivitas sosialisasi, akan lebih dibudayakan dengan penuh kesadaran, terencana dan terekspos dalam pembelajaran.

6. Faktor-faktor apa saja yang dipandang sebagai hal yang mempengaruhi terbentuknya keterampilan sosial, diawali dengan penilaian ini akan memberikan inspirasi secara lebih luas

7. Bahasa belum digunakan secara optimal untuk meningkatkan 
keterampilan sosial, padahal jika kita ingin membantu anak menguasai sebuah area tertentu, salah satu strategi belajar yang dapat dilakukan adalah memperbanyak penguasaan kosa kata yang terkait dengan area itu. Termasuk belum sepenuhnya dimanfaatkan bagi pengembangan keterampilan sosial

8. Pada umumnya secara luas, asesmen keterampilan sosial baru difahami sebatas pengertian kognisi sosial. Sehingga asesmen yang dipakai kali ini tidak hanya mengukur hal-hal yang bersifat verbal.

\section{b. Manfaat Penilaian}

Perangkat penilaian yang akan dikembangkan ini dapat dipakai sebagai alat diagnosis atau pemeriksaan defisit keterampilan sosial, dan dapat dipakai sebagai acuan pembelajaran keterampilan social.

\section{Daftar Pustaka}

APEID(1993) New Directions in Technical and Vocational Education, Bangkok : Unesco Regional Office for Asia and Pasific

Allen, Mary. Yen \& Yen, Wendy. M(1979). Introduction measurement theory, Berkeley, California: Brooks/ Cole Publishing Company

Amaury Samalot - Rivera M.A. 2007, The Effect Of Social Skill Instruction On Sport And Game Related Behaviors Of Children And Adolescents With Emotional Or Behavioral Disorders Dissertation
Presented In Partial Fulfillment Of The Requirements For The Degree Doctor Of Philosophy In The Graduate School Of The Ohio State University, The Ohio State University

Andersen, Lorin. W. (1981). Assessing Affective Characteristic in The Schools.Boston: Allyn and Bacon.

Ayriza, Y., lzzaty, R. E. \& Setiawati, F., A., (2004-2006). Pengembangan modul social skilluntuk anak-anak prasekolah dan model sosialisasinya. Yogyakarta : Pusdi PAUD.

Bandura, A. (1986). Social foundations of thought and action: A social cognition theory. New Jersey : Prentice Hall, Inc.

Brennan, R. L. (Ed.). (2006). Educational Measurement. $4^{\text {th }}$ Edition. Wesport, CT: American Council in Education \& Praeger Publishers

Cavell, T. A. (1990). Social adjustment, social performance, and social skill: A tri- component model of social competence. Journal of Clinical Child Psychology, 19, 111-122. (20)

Curtis, A. (1998). A curriculum for the pre-school child. New York: Routledge. 
Cohen, R. J., \& Swerdlik, M. E. (2005). Psychological testing and assessment. $6^{\text {th }}$ Edition. New York, NY: McGraw-Hill Companies, Inc.

Crocker, L, \& Algina, J. (1986). Introduction to classical and modern test theory. Madison Avenue, New York, NY: Holt, Rinehart \& Winston.

Djohan, Jurnal Penelitian dan Evaluasi Pendidikan Vol. 13, No. 1, Thn. 2009 (12)

Eisenberg, N., Cameron, E., Tryon, F,, \& Dodez, R (1 98 1). Socialization of prosocial behavior in the preschool classroom. Developmental Psychology, 17, 773-782. . (43)

Emmer, E.T. (1986). Effects of teacher training in disciplinary approaches. Washington, DC: U.S. Department of Education, Office of Educational Research and Improvement. (ERIC Document Reproduction Service No. ED 316 927)(44)

Franz, C. E., Mc. Clelland, D. C., Weinberger, J. (1991). Childhood antecedents of convetional school accomplishment in midlife adults. Journal of Personality and Social Psychology, Vol. 60, page 586-595.

Furr, R. M., \& Bacharach, V. R. (2008). Psychometrics: An introduction. Thousand Oaks, California: Sage Publications, Inc
Gettinger, M. (2001). Development and implementation of a Performance-Monitoring System for Early Childhood Education. Early Childhood Education Journal, Vol 29, No. 1.

Gymboree: A Solution for Socialization, Parental Support Gymboree: National Survey of 350 Preschool Teachers Finds Social Skills Trump Academic Abilities." $P R$ Newswire. $P R$ Newswire Association LLC. 2006. HighBeam Research. 26 Apr. 2010 <http://www.highbeam.com > (51)

Goldstein (1981), Goldstein, A. P., 1981, Psychological Skill Training, The Structured Learning Technique. New York 38

Goleman,Daniel $2007 \quad$ Social Intelligence New Science Of

Human

Relationships, B antam Dell,NY,USA (11)

Gregory, R. J. (2007). Psychological testing: History, principles, and applications. $5^{\text {th }}$ Edition. Boston, MA: Allyn \& Bacon

Halpern, D. F. (n.d.) Creating cooperative learning environments. American Psychological Society. Retrieved December 5, 2005 from http://www.psychologicalscien ce.org/teachingtips/tips/tops_0 300.html 
Hambleton, R. K., Swaminathan, H., \& Rogers, H. J. (1991).

Fundamentals of item response theory. Newbury Park, California: Sage Publications, Inc.

Hannaford, Carla 2005,Smart Moves : Why Learning Is Not All In Your Head ,Great River Books (Formerly Graat Ocean Publishers). Great River Books I6i M Street Salt Lake City, Utah 84103 www greatriverbooks.com Page 173(28)

Kerjasama Antara Kemdiknas Dirjrn Dikti Diktendik,(2007), Konsep Dasar Pendidikan Kecakapan Hidup, Buku 2 seri Pendidikan Kecakapan Hidup Unesco Jakarta Office

KR, Rabu Wage (25 April 2012), PAUD Kulonprogo Peringkat IV Indonesia. YOGYA

KR,Senin (23/4 2012) Rama Yusufa Juara Lomba Mewarnai. YOGYA

Ladd, G. W. (1990). Having friends, keeping friends, making friends, and being liked by peers in the classroom: Predictors of children's early school adjustment? Child Development, 6 1, 312-331.( 44)

Ladd, G. W., \& Golter, B. (1988).

Parents' management of preschoolers' peer relations: Is it related to children's social competence? Developmental Psychology, 24, 109-117.
Ladd, G. W., \& Price, J. M. (1987). Predicting children's social and school adjustment following the transition from preschool to kindergarten. .) 44)

Linn, R. L. (1989). Educational measurement. $3^{\text {rd }}$ Edition. New York, NY: Macmillan Publishing Company

Lawhon, T., Lawhon, D. C. (2000).Promoting social skill in young children. Early Childhood Education Journal, Vol. 28, No. 2.

Mardapi, Djemari.2007.Teknik Penyusunan Instrumen Tes dan Nontes.Yogyakarta : Mitra Cendekia

Mardapi Djemari (2008) Teknik Penyusunan Instrumen Tes Dan Nontes Mitra, Jogjakarta Mitra Cendikia Offset

Mayeux, L., Cillessen, A. H. N. (2003).Development of social problem solving in early childhood. The Journal of Genetic Psychology, 162 (2), 153-173.

Monks, F.J., Knoers, A. M. P., \& Haditono, S.R. (1998). Psikologi Perkembangan. Yogyakarta : Gadjah Mada University Press.

Mize, J. (1995). Coaching preschool children in social skills: A cognitive-social learning curriculum. In G. Carteledge, \& J. F. Milbum (Eds.).

Teaching social skills to 
children and youth: Innovative approaches. 237-261. Third edition. Boston, MS: Allyn and Bacon

Nonny Swediati, 2007, Optimalisasi Multiple Intelligences Dengan Brain Gym

Peraturan Menteri Pendidikan Nasional Republik Indonesia Nomor 16 Tahun 2007

Peraturan Menteri Pendidikan Nasional Republik Indonesia:Nomor 58 Tahun 2009 Tentang Standar Pendidikan Anak Usia Dini.( 42)

PRNewswire/ January 10, 2006. /-Character Development - Not Reciting ABCs - is Key to Toddlers' Success in Preschool(tsp)National Survey of 350 Preschool Teachers Finds Social Skills Trump Academic Abilities. Article from: $P R$ Newswire. Article date: More results for:social ability Character Development - Not Reciting ABCs - is Key to Toddlers' Success in Preschool SAN FRANCISCO, (45)\

Purwanto.2006.Instrumen Penelitian Sosial dan Pendidikan. Yogyakarta : Pustaka PelajarPeterson, Brooks, 2004 Cultural Intelligence : A Guide To Working With People From Other Cultures(18)

Published by HT Syndication with permission from Asian News International"How childhood experiences may influence social skills, ability to handle stress." The Hindustan Times. HT Media Ltd. 2008.

HighBeam Research. 26 Apr. 2010

<http://www.highbeam.com>. How childhood experiences may influence social skills, ability to handle stress Article from: The Hindustan Times Article date:July 30, 2008 More results for: social ability Report from Asian News International brought to you by HT Syndication. (47)

\section{"RESEARCH LINKS CHILDHOOD} SOCIAL SKILLS, LEARNING ABILITIES." US

Fed News Service, Including US State News. HT Media Ltd. 2007. HighBeam Research. 26

Apr. 2010 $<$ http://www.highbeam.com>. Research Links Childhood Social Skills, Learning Abilities Article from:US Fed News Service, Including US State News Article date:June 19,2007More results for:social ability (48)

Ramdhani, N. (1991). Standarisasi skala tingkah laku sosial. Laporan Penelitian. Yogyakarta : Fakultas Psikologi UGM.

Ringwalt, S. (2008). Developmental screening and assessment instruments with an emphasis on social and emotional development for young children ages birth through five. Chapel Hill: The University of North Carolina, FPG Child Development 
Institute, National Early

Childhood Technical

Assistance Center.

http://www.nectac.org/ pdfs/p

ubs/screening.pdf

Rick Lavoie (2005) Social Skill

Autopsies: A Strategy to

Promote and Develop Social

Competencies.

http://www.ldonline.org/article

/Social_Skill_Autopsies\%3A

A_Strategy to_Promote and

Develop_Social_Competencies

Roid, Gale $\mathrm{H}$ and Thomas $\mathrm{M}$. Haladyna. (1982). A Thechnology for Test-Item Writing. London: Academic Press, Inc

Robin Stern, Ph.D What is it? How can we use it to help our children? by Robin Stern, Ph.D. Social and Emotional Learning: Robin Stern, Ph.D.(22)

Roeser, R. W., Wolf, K. V. D., Strobel, K. R. (2001). On the relation between socialemotional and school functioning. Journal of School Psychology, Vol. 39, No. 2, pp 111-139.

Seto Mulyadi, 2007, Tak Mempan

Digertak Anjuran, Pena

Pendiddikn
Sidiarto Lily Djokosetio, 2007, Perkembangan Otak Dan Kesulitan Belajar Pada Anak Jakarta: Penerbit Universitas Indonesia (UI-Press)

Shultz, K. S., \& Whitney, D. J. (2005). Measurement theory in action: Case studies and exercises. Thousand Oaks, California: Sage Publications, Inc.

(Social Skills: Promoting Positive Behavior, Academic Success, and School Safetyhttp://www.nasponline.or $\mathrm{g} /$ resources/factsheets/socialski lls_fs.aspx) 33

Stormshak, E. A., welsh, J. A. (2005). Social competence : A developmental framework. In Teti, D. M. I. Handbook of Research Methods in Developmental Science.

Australia: Blackwell Publishing.

Thiagarajan, S., Semmel, D. S., \& Semmel, M. I. (1974). Instructional development for training teachers of exceptional children: A sourcebook. Mineapolis, Minesota: CITH Indiana University dan CEC 